\title{
Transient Changes in Excitability of Rabbit CA3 Neurons With a Time Course Appropriate to Support Memory Consolidation
}

\author{
L. T. THOMPSON, J. R. MOYER, JR., AND J. F. DISTERHOFT \\ Department of Cell and Molecular Biology and The Institute for Neurosciences, Northwestern University Medical \\ School, Chicago, Illinois 60611
}

\section{SUMMARY AND CONCLUSIONS}

1. The excitability of CA3 pyramidal neurons was assessed with intracellular recordings in hippocampal slices from behaviorally naive rabbits. CA3 pyramidal neurons had large $(-13.1 \pm 0.3$ $\mathrm{mV}$; mean $\pm \mathrm{SE}$ ) postburst afterhyperpolarizations (AHPs) and exhibited robust spike-frequency adaptation (accommodation) to prolonged (800-ms) depolarizing current injection at resting potentials of $-68 \mathrm{mV}$. AHP and accommodation measures differed in scale but not in kind from those obtained in stable recordings from CA1 pyramidal neurons in the same slices or from the same rabbits, with CA3 neurons having larger longer AHPs but fewer spikes during accommodation.

2. Groups of rabbits were trained in a simple, associative-learning task, trace eye-blink conditioning, which requires an intact hippocampus for successful acquisition. Memory consolidation in this task also involves the hippocampus, whereas long-term retention of the learned response does not. The time course and magnitude of learning-specific changes in excitability were assessed in $201 \mathrm{CA} 3$ pyramidal neurons.

3. Learning increased the excitability of CA3 pyramidal neurons soon after acquisition (within 1-24 h). The mean postburst AHP was reduced to approximately half $(-6.4 \pm 0.3 \mathrm{mV})$ the basal amplitude of the AHP observed in naive controls. The area and duration of the postburst AHP similarly were reduced. Approximately half of all pyramidal neurons tested soon after learning exhibited significantly reduced AHPs, whereas none exhibited enhanced AHPs.

4. Trace conditioning also reduced accommodation of CA3 pyramidal neurons $1-24 \mathrm{~h}$ after learning. Neurons from successfully trained rabbits fired significantly more action potentials $(5.6 \pm 1.5)$ in response to prolonged depolarization than did neurons from naive controls $(4.1 \pm 0.2)$. The magnitude of the learning-specific change in accommodation was less than that for the AHP. Approximately $45 \%$ of neurons tested exhibited significantly reduced accommodation soon after learning.

5. Both learning-specific changes in CA3 increased neuronal excitability. Both changes were highly time dependent. AHPs were reduced maximally $1-24 \mathrm{~h}$ after lcarning, then increased, returning to basal (naive) levels within 7 days and remaining basal thereafter. The decay rate of accommodation to basal levels preceded that of the AHP by several days.

6 . Other membrane properties, including action potential characteristics, resting potential, and input resistance, were unchanged by learning. The restriction of the observed changes to two interrelated measures of excitability concurs with earlier reports that learning-specific changes in the mammalian hippocampus are linked to changes in a limited number of membrane conductances.

7. Learning, not long-term memory or performance of the learned behavior, was linked to the excitability changes. Neurons from rabbits that failed to acquire the task after considerable training exhibited no excitability changes. Neurons from pscudoconditioned rabbits were indistinguishable from neurons of behaviorally naive controls. Finally, neurons from rabbits that explicitly demonstrated long-term retention of the conditioned response were indistinguishable from those of naive controls.

8. Behavioral changes persisted for extremely long periods, but the observed changes in hippocampal excitability were transient and greatest soon after lcarning. Excitability was enhanced for a period of a few days, a period demonstrated in other eyeblink studies to be required for memory consolidation. Because hippocampal excitability then returned to basal levels but memory of the learned task persisted, postconsolidation memory traces (the "engram") must be extrahippocampal.

\section{INTRODUCTION}

Neuronal plasticity is a nonspecific mechanism generally assumed by neurobiologists to underlie the changes in behavior that are termed learning and memory. Most current learning theories focus nearly exclusively on models of synaptic potentiation as a preferred mechanism contributing to this plasticity (Barnes 1995; Carew and Sahley 1986; Hawkins et al. 1993; Hebb 1949) although controversy surrounds attempts to link such models to associative learning in vertebrates. In some vertebrate learning tasks, including spatial learning and eye-blink conditioning, synaptic plasticity has been demonstrated during or after learning (Berger 1984; Bloch and Laroche 1994; Green and Greenough 1986; LoTurco et al. 1988; Power et al. 1995). However, the reverse has not been convincingly demonstrated, i.e., synaptic plasticity has produced sharply inconsistent cffects on lcarning (Castro et al. 1989; Jeffery and Morris 1993; Korol et al. 1993; Rioux and Robinson 1995; Robinson 1992; Sharp et al. 1985; Sutherland et al. 1993). Specific links between long-term synaptic potentiation and long-term behavioral plasticity remain mostly hypothetical (see review of theoretical and practical issues in Barnes 1995). LoTurco et al. (1988) suggested that both synaptic potentiation and other, perhaps related, postsynaptic mechanisms may be involved in learning-related plasticity soon after learning. Very consistently, an increase in the excitability of hippocampal neurons has been reported in vivo during and shortly after associative learning (Berger et al. 1976, 1983; Breese et al. 1989; Christian and Deadwyler 1986; Eichenbaum et al. 1989a,b; Olds et al. 1972; Segal et al. 1972). Although these are not the only neurons changed by association (e.g., Thompson 1986), the robust plasticity of hippocampal neurons observed across multiple behavioral tasks has focused attention on the role of the hippocampus in learning. Hippocampal neurons thus may serve as a useful model to account for alterations in neuronal firing rates with learning. 
Alternate hypotheses (other than synaptic potentiation) explaining hippocampal plasticity are infrequently examined, although there is no a priori reason why synaptic potentiation should be the sole nor the primary conserved mechanism of plasticity in the nervous system. For example, conditioningspecific increases in postsynaptic excitability after blockade of $\mathrm{Na}^{+}$-dependent synaptic transmission have been demonstrated in vitro in a vertebrate model learning system (Coulter et al. 1989) and are consistent with increased neuronal firing rates in vivo. Specifically, the postburst afterhyperpolarization (AHP) evoked by intracellular (i.e., nonsynaptic) depolarizing current injection is reduced in hippocampal CA1 pyramidal neurons from delay dependent (Coulter et al. 1989; Disterhoft et al. 1986; Sanchez-Andres and Alkon 1991), 300-ms trace dependent (de Jonge et al. 1990), and hippocampally dependent 500-ms trace eye-blink-conditioned rabbits (Moyer et al. 1996), but not from pseudoconditioned or behaviorally naive controls. The postburst AHPs of dentate granule (DG) cells apparently are unaffected after conditioning (de Jonge et al. 1990). The postburst AHP in hippocampal pyramidal neurons is generated largely by a $\mathrm{Ca}^{2+}$-dependent $\mathrm{K}^{+}$current, $I_{\mathrm{AHP}}$ (Hotson and Prince 1980; Lancaster and Adams 1986; Storm 1990), which in isolation is voltage and tetraethylammonium (TEA) insensitive but is reduced by cholinergic agonists (Knöpfel et al. 1990; Madison et al. 1987). Potassium conductances such as $I_{\mathrm{AHP}}$ play important roles in regulating neuronal membrane potentials after spike firing events (Storm 1990). Learning-specific reductions in two $\mathrm{K}^{+}$conductances were first reported in conditioned Hermissenda preparations (Alkon 1979, 1984; Alkon et al. 1982) and may indicate a broadly conserved mechanism contributing to behavioral plasticity (Alkon et al. 1987). Reductions in $I_{\text {AHP }}$ but not in other $\mathrm{Ca}^{2+}$-dependent $\left(I_{\mathrm{C}}\right)$ or cholinergic-sensitive $\left(I_{\mathrm{M}}\right) \mathrm{K}^{+}$currents have been demonstrated after rabbit eye-blink conditioning in single-electrode voltage-clamp studies (Sanchez-Andres and Alkon 1991).

The excitability of CA3 pyramidal cells after conditioning has not been studied in vitro, although in vivo evidence indicates that CA3 excitability is enhanced in a fashion analogous to that observed in CA1 (Berger et al. 1976, 1983). Further, the time course of changes in excitability in either CA1 or CA3 after learning is ill defined. Although behavioral changes (memory after learning) can persist for long periods without subsequent training, many functional models posit that the hippocampus serves only as a short- rather than a long-term memory storage site (Cohen and Eichenbaum 1993; Squire 1987). In fact, models of learning that explain the phenomenon of retrograde amnesia suggest that a process termed memory "consolidation" transfers information from short- to long-term stores (Bloch 1970; McGaugh 1966). Disruptions interfering with neuronal activity during this consolidation interval (either permanent disruptions, via lesions, or transient ones, via electroconvulsive shock) block this transfer (McGaugh and Alperin 1966) and prevent learning of some tasks, as do disruptions instituted before training occurs (Moyer et al. 1990; Solomon et al. 1986). In trace eye-blink conditioning, data suggest that hippocampal function can be blocked without altering retention of previously learned responses only if the disruption occurs relatively long after training (Kim et al. 1995). Lesions or disruptions occurring soon after acquisition disrupt long-term retention of the learned task. These data suggest several hypotheses about hippocampal function in learning.

The current study was designed to test a number of these hypotheses. Different hippocampal cell populations (CA1 vs. DG) appear to respond differentially to learning. Is CA3 more like CA1 or DG, i.e., is excitability increased or unchanged in CA3 after learning? Are changes in excitability related to learning, to performance, or to memory of the learned response? The time course of excitability changes should parallel deduced functional requirements of the hippocampus (Byrne 1987). Are changes in excitability time dependent and cease to persist when no longer required?

To address these questions, the excitability of CA3 neurons in vitro was examined in slices prepared from behaviorally naive or from trained rabbits. Hippocampal excitability was probed at a number of time intervals after learning to determine if CA3 changed after learning and whether changes paralleled the time course of other bchavioral events relative to the learned behavioral response. A number of behavioral controls also were used to assess the issue of specificity of these changes in CA3 function to learning, to consolidation, to performance, or to memory (long-term retention) processes. Concurrent studies of the time course of learning-related excitability changes observed in CA1 pyramidal neurons were reported in Moyer et al. (1996).

\section{METHODS}

\section{Behavioral training and definition of learning-related groups}

Animal care was in accordance with guidelines established by the USDA and approved and managed by Northwestern University's Animal Care Committee. For recording, 78 young (6-8 wk) NZW rabbits (Oryctolagus cuniculus) were either trace conditioned $(n=51)$, pseudoconditioned $(n=12)$, or received no behavioral training (naive controls, $n=15$ ), as previously described (Thompson et al. 1992, 1996). To summarize, rabbits were fitted surgically with restraining headbolts, allowed $48 \mathrm{~h}$ for recovery, were habituated to passive restraint in the training environment, and then were trained in pairs in individual sound-attenuated chambers with stimulus presentation and data acquisition controlled by a system detailed elsewhere (Akase et al. 1994; Thompson et al. 1994). Trace conditioning consisted of daily 80 trial sessions pairing a $100-\mathrm{ms}$, $85-\mathrm{dB}, 6-\mathrm{kHz}$ pure tone conditioned stimulus (CS) followed after a 500-ms tracc interval with a 150-ms, 3-psi corneal airpuff unconditioned stimulus (US). Trials occurred on average every $45 \mathrm{~s}$. Trace conditioned rabbits were trained to a criterion of $\geq 80 \%$ conditioned responses (80\% CRs) per 80-trial session, a standard criterion for successful acquisition of the learned response (Disterhoft et al. 1977; Kim et al. 1995; Moyer et al. 1990; Thompson et al. 1996) or were studied separately if they failed to reach criterion within 15 sessions (see Disterhoft et al. 1988 and below). Pseudoconditioning consisted of equal numbers of unpaired presentations of the same CS and US used in conditioning but at pseudorandom intervals, averaging $22.5 \mathrm{~s}$ between stimulus presentations. Pseudoconditioning is commonly used to control for nonspecific effects of stimulus presentation not directly related to associative learning (Baranyi et al. 1991; Gormezano and Kehoe 1980).

Together with the pseudoconditioned and naive controls described above, neuronal excitability was evaluated for a total of 10 groups. To evaluate the time course of learning-related changes in hippocampal electrophysiology and to compare these changes 
with long-term retention of the CR, successfully trace conditioned rabbits were separated randomly into seven groups. The first six of these groups were composed of rabbits killed for recording at intervals of 1 or $24 \mathrm{~h}$ or $3,5,7$, or 14 days after reaching criterion. Notably, no significant differences were observed in learning rates (i.e., trials to criterion) between any of these trace conditioned groups $(P>0.3)$. Another (the 7 th) trace-conditioned group was trained to criterion, then held for 13 days without additional training. On the 14th day, one session of 80 paired CS-US trials was given; $24 \mathrm{~h}$ later, slices were prepared for study. Slow-learning rabbits (an additional subset of 7 rabbits that were trace conditioned, but exhibited $<30 \%$ CRs after $\geq 15$ training sessions) were subdivided, and part of this group (the 8th; $n=4$ ) served as a control group for learning-specific changes in CA3 excitability and were killed for recording $24 \mathrm{~h}$ after their final training session. The remaining three slow-learners were switched after 15 sessions of trace conditioning to a simpler delay-conditioned eye-blink task (400-ms tone CS, coterminating with a 150-ms airpuff US; all other parameters as in trace conditioning). No physiological data was gathered from this group after acquisition. A separate group of rabbits $(n=7)$ were trace conditioned to critcrion, then used to test behavioral retention. This group received 20 paired CS-US trials at selected intervals at probe sessions, with several individuals each tested at intervals $24 \mathrm{~h}$ to $6 \mathrm{mo}$ after reaching criterion with each rabbit tested for retention performance a maximum of four times. No physiological data were gathered using this group.

Off-line analyses of the physiological data were made blindly; as noted below, all cells meeting minimal criterion for cell health after initial impalement were used without exceptions. However, the recordings were not made using blind procedures relative to the behavioral conditions, for three primary reasons. First, numerous prior blind studies of conditioning-specific postsynaptic changes in neuronal excitability have yielded results consistent with the current findings, both from our own laboratory (de Jonge et al. 1990; Disterhoft et al. 1986, 1988) and from others (Coulter et al. 1989; LoTurco et al. 1988; Sanchez-Andres and Alkon 1991; Woody et al. 1991). Second, blind procedures have not been systematically used in similar studies in the invertebrate learning literature (e.g., Carew et al. 1979) and certainly have not been the rule (e.g., Castellucci et al. 1970; Hawkins et al. 1983; Walters and Byrne 1983). Finally, and most pragmatically, the random variation in acquisition rates between rabbits and the large number of groups tested required constant evaluation to minimize the number of subjects required for training, to assure adequate samples of neurons in cach testing group, to avoid cohort cffects, and to balance behavioral variables such as trials to criterion between groups. Under blind conditions, valuable subjects would have to have been discarded (only data from 1 subject per day could be collected); in practice, on many days three or more subjects were available for recording, and judicious assignment of rabbits to different test groups (or reassignment from previous schemes due to behavioral results occurring within the hour) precluded blinding. After weighing the theoretical and practical issues outlined above, we determined that sacrificing large numbers of valuable rabbits indiscriminately to satisfy arbitrary notions of ideal experimental conditions would have been both wasteful and inhumane. The findings must therefore be evaluated in consideration of these points.

\section{Slice preparation}

Hippocampal slices were prepared using procedures similar to those previously published (Moyer et al. 1992). Briefly, rabbits were anesthetized with halothane then decapitated. The brain was exposed, quickly hemisected in vivo, removed (within $50 \mathrm{~s}$ ), and placed in ice-cold $\left(<1^{\circ} \mathrm{C}\right)$ oxygenated sucrose-substituted artificial cerebrospinal fluid [sucrose-ACSF, its composition was (in $\mathrm{mM}$ ) 248 sucrose, $3 \mathrm{KCl}, 1.3 \mathrm{MgSO}_{4}, 1.24 \mathrm{NaH}_{2} \mathrm{PO}_{4}, 2.4 \mathrm{CaCl}_{2}, 26$
$\mathrm{NaHCO}_{3}$, and $10 \mathrm{D}$-gluciose, gassed with $95 \% \mathrm{O}_{2}-5 \% \mathrm{CO}_{2}$ with $\mathrm{pH}$ 7.4) for $\sim 3 \mathrm{~min}$. This $\mathrm{Na}^{+}$-free sucrose-ACSF was used to minimize anoxic impact during slice preparation (see Aghajanian and Rasmussen 1989). Both hippocampi quickly were dissected out, and 5-mm transverse chunks were submerged in ice-cold sucrose-ACSF. Dorsal hippocampus slices $(400 \mu \mathrm{m})$ were cut on vibratomes. Slices were held in normal ACSF $(124 \mathrm{mM} \mathrm{NaCl}$ in place of sucrose) at room temperature for $\geq 45 \mathrm{~min}$ before recording, typically yielding three to five stable CA3 pyramidal neuron recordings per subject during the succeeding 6 -h period.

\section{Electrophysiological recordings}

Intracellular recordings were made using an Axoclamp-2A amplifier (Axon Instruments) with the bridge balanced whenever intracellular current was injected. Thin-walled glass microelectrodes were filled with either $3 \mathrm{M} \mathrm{KCl}(35-55 \mathrm{M} \Omega$ ) or $2 \%$ neurobiotin in $3 \mathrm{M} \mathrm{KCl}(60-80 \mathrm{M} \Omega)$ and used for recording. Slices were transferred individually to a submersion chamber (Medical Systems) and continuously perfused $(\sim 1.7 \mathrm{ml} / \mathrm{min})$ with oxygenated $31^{\circ} \mathrm{C}$ ACSF. Data from all CA3 neurons were collected for study if they exhibited little spontaneous activity at rest and were stable for $\geq 5$ min before the experimental protocol, had an evoked action potential amplitude $>85 \mathrm{mV}$ from rest, had an input resistance $\geq 35 \mathrm{M} \Omega$, and had a resting membrane potential between -62 and $-72 \mathrm{mV}$. Pyramidal neurons were later separated from nonpyramidal neurons (probable interneurons) using the criteria that pyramidal cells had an action potential duration $>1.2 \mathrm{~ms}$ from rise threshold to recrossing the resting potential, fired $<12$ action potentials during accommodation testing, and had a postburst AHP rather than an afterdepolarization. Neuronal responses were studied at membrane potentials of $-67 \pm 2 \mathrm{mV}$ to minimize the contribution of extraneous voltage-dependent conductances on measures of excitability. Cells filled with neurobiotin for positive histological as well as physiological identification were aldehyde fixed and processed for visualization with Vectastain ABC kits (Vector Laboratories). Filled cells were examined with light microscopy and drawn with a camera lucida from an examination of all focal planes. Approximately $96 \%$ of CA3 neurons recorded were impaled in area CA3a, near the dorsal edge of the fimbria, whereas $4 \%$ were impaled in CA $3 b$ or between these two areas (see Lorente de Nó, 1934; Scharfman 1994). No systematic variation in region studied occurred between behavioral groups.

Membrane properties were studied under current clamp. Currentvoltage $(I-V)$ relations were studied using 400-ms current steps from rest (range: -1.0 to $+0.2 \mathrm{nA}$ ). Input resistance was determined by measuring the plateau voltage deflection during the last $75 \mathrm{~ms}$ of a 400-ms - 0.2-nA hyperpolarizing step. The depolarizing sag was calculated as the difference between the peak negative potential and the plateau potential response during the final $75 \mathrm{~ms}$ of a - 1.0-nA hyperpolarizing step. The postburst AHP was studied five times at 15 -s intervals and was evoked by a 100 -ms depolarizing step from rest adjusted as minimally sufficient to reliably elicit a burst of four action potentials. The duration of the AHP was measured from stimulus offset until the potential returned to the resting potential for $\geq 10 \mathrm{~ms}$. The pcak AHP amplitude was calculated as the maximal negative potential deviation from rest during the first $250 \mathrm{~ms}$ after current offset. The integrated area of the AHP was calculated from current offset for the entire duration of the AHP. Spike frequency adaptation (accommodation) was studied using an 800-ms depolarizing current step of the same stimulus intensity used to evoke the AHP. The number of action potentials elicited was noted three times at 30-s intervals. Action potential peak amplitudes were measured relative to resting potential for single spikes and the width was measured at one-third peak amplitude. Resting membrane potential was calculated as the potential difference before and after microelectrode withdrawal. Data from 
no more than two CA3 cells were recorded from a given slice (in some experiments, both a CA3 and a CA1 pyramidal cell in the same slice were evaluated consecutively). The slice was changed if a cell was lost during an experiment, if more than five penetrating tracks were attempted, or after completion of the second experiment. Data from cells lost during an experiment were not included.

All data were stored digitally on video cassette, after conversion by a digital data recorder (Instrutech). Data were analyzed off-line using a Lab-NB (National Instruments) Macintosh interface and custom software. Analog-to-digital sampling rates were $5 \mathrm{kHz}$ for $I-V$ relations and AHPs, $10 \mathrm{kHz}$ for accommodation measures, and $1 \mathrm{kHz}$ for membrane potentials. Digitized data were analyzed blindly off-line using IGOR Pro (WaveMetrics). Statistical analyses were performed using analyses of variance for repeated measures (StatView, Abacus Concepts), with behavioral treatment groups detailed above. Significant main effects were evaluated using Scheffe post hoc tests. All data are reported as means $\pm S E$.

\section{RESULTS}

\section{Behavioral acquisition and retention of the conditioned eye-blink}

Acquisition to criterion required an average of $513 \pm 21$ trials (see Fig. 1). Pseudoconditioned control rabbits exhibited no increase in performance of CRs (i.e., blinks occurring within $600 \mathrm{~ms}$ after unpaired tone onset) from the first to the last session of pseudoconditioning (paired $t$-test, $P>$ 0.3 ). Trace-conditioned rabbits, however, clearly increased their CRs (with a mean latency after tone onset of $383 \pm$ $44 \mathrm{~ms}$ ) with successive training (paired $t$-test, $P<0.001$ ). Additionally, there was no statistically significant difference in CR performance between rabbits that were trace- or pseudoconditioned during their first training session (paired $t$-test, $P>0.2$ ). This suggests that subsequent learning-specific changes in neuronal excitability were not due to preexisting behavioral differences in the rabbit populations sampled. Rabbits learn the trace-conditioned eye-blink task much more slowly than simpler delay-conditioned tasks, even when the same duration conditional stimuli are used (see Thompson et al. 1996). In trace conditioning, large numbers of repeated associative pairings of the CS and US are required before rabbits exhibit evidence of learning. As noted, the trace conditioned task requires an intact hippocampus (Moyer et al. 1990; Solomon et al. 1986), whereas the delay conditioned task is predominantly dependent upon cerebellar integrity (McCormick et al. 1982; Thompson 1986).

In this and past studies in our laboratory, it has been noted that a very small proportion (typically $<5 \%$ ) of young rabbits selected for trace conditioning fail to acquire the conditioned eye-blink, even after training greatly in excess of that typically required. As seen in Fig. 1, in the current study, these rabbits failed to demonstrate a significant increase in CRs between their first and their final training session (paired $t$-test, $P>0.2$ ) and thus appear to be an ideal control for learning - rather than training - specific changes in excitability. Three slow-learning rabbits were switched from trace to delay conditioning, which is not hippocampally dependent. The switched rabbits reached criterion in the simpler delay task within 320 trials. Similar results also have been reported when slow-learning aging rabbits were switched from trace to delay conditioning (Thompson et al. 1996).
Once acquired, the trace-conditioned eye-blink response was remarkably stable. Criterion performance was maintained at all intervals tested after rabbits reached a criterion of $80 \%$ CRs per session. Retention was tested with 20 trial probe sessions at intervals from 1 day to 6 mo after acquisition, with no decline below criterion performance $\left(F_{9,22}=\right.$ $0.85, P>0.5$ ). Additionally, all rabbits used to demonstrate the effects of long-term retention on hippocampal excitability in experiments detailed in later sections displayed asymptotic behavior during retention testing (i.e., during a final testing session 14 days after initial acquisition, with no intervening training). This long-term behavioral stability differs prominently from the transient excitability changes detailed below.

\section{Identification of CA3 pyramidal neurons}

Intracellular recordings were made from 213 neurons with stable resting potentials in CA3 stratum pyramidale (Fig. 2). The postburst AHP and spike frequency accommodation evoked by depolarizing current injection as well as action potential characteristics were examined. Input resistance measures obtained from linear fits of membrane currentvoltage curves or from plateau responses to 0.2-nA hyperpolarizing pulses were compared, and the two measures yielded nearly identical values $(P>0.4)$. Neurons were classified as pyramidal neurons (201 of 213) or as basket cells or other interneurons (12 of 213) based upon the criterion defined above. Few (3 of 12) nonpyramidal neurons exhibited any postburst AHP, with the highest amplitude only $-2.4 \mathrm{mV}$, considerably less than half the smallest AHP amplitude observed for any pyramidal neurons in any of the behavioral conditions detailed below. The current required to evoke four spikes from nonpyramidal neurons was very near threshold for firing a single action potential. The same current intensity in nonpyramidal neurons often produced variable numbers of spikes from burst to burst, unlike in pyramidal neurons, which required progressively more depolarizing current to evoke more spikes per burst and produced reliably stable spike counts at fixed intensities in all behavioral conditions. The soma of filled basket cells were typically one-third or less the cross-sectional diameter of pyramidal neurons and exhibited extensive neurite proliferation within the pyramidal cell layer, whereas pyramidal neurons exhibited stereotypic apical and basal dendritic arborization with no neurite proliferation within the cell body layer. No learning-specific differences in gross architecture of pyramidal neurons were observed (quantitative analysis was not attempted due to the relatively limited number of filled neurons available for study). Physiological measures from pyramidal neurons only are reported below.

\section{CA3 pyramidal cell excitability in behaviorally naive controls}

CA3 pyramidal neurons in slices prepared from behaviorally naive rabbits exhibited large-amplitude $(-13.1 \pm$ $0.3 \mathrm{mV})$ and long-duration $(9,109 \pm 121 \mathrm{~ms})$ postburst AHPs (see Fig. 3A). The amplitude of the observed AHPs were remarkably stable between repetitions of the same intensity brief $(100 \mathrm{~ms})$ depolarization. CA3 AHP ampli- 


\section{A Acquisition}

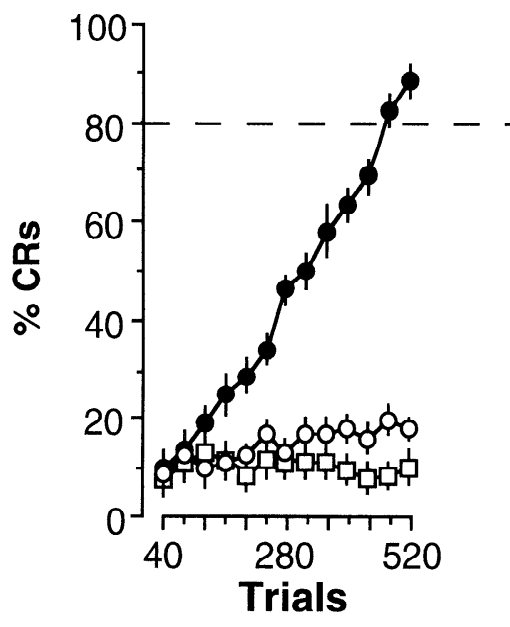

B

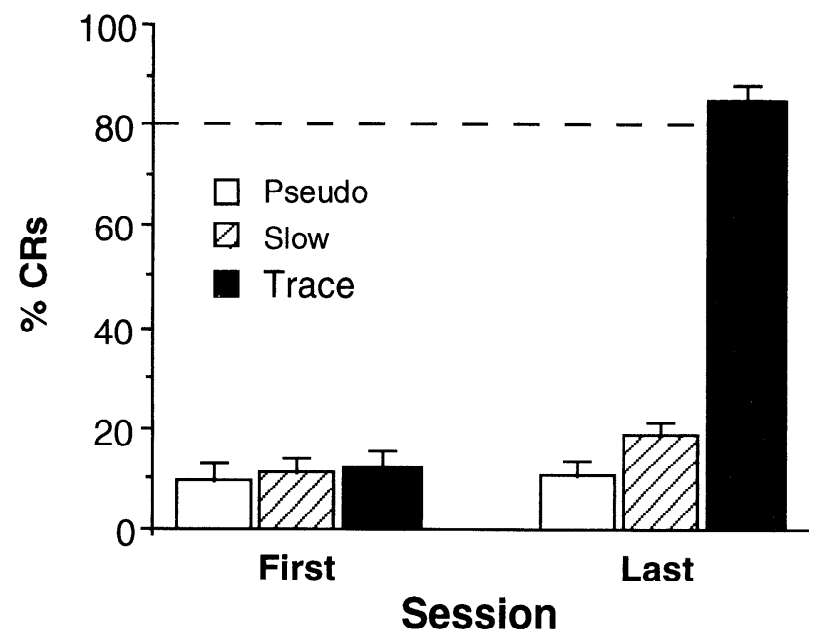

\section{Acquisition}

Session
Retention

\author{
- Trace \\ 口 Pseudo \\ - Slow
}

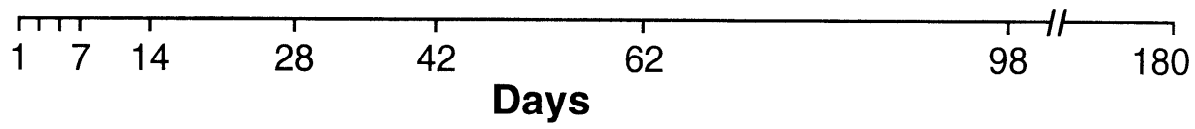

C Retention

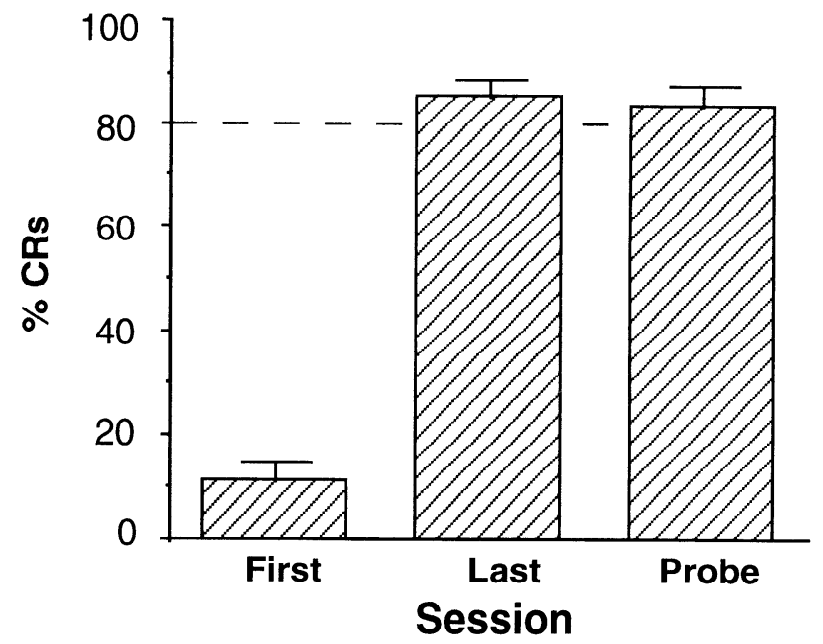

FIG. 1. Behavioral data indicated that trace but not pseudoconditioned or slow-learning rabbits successfully acquired the trace eyeblink task and retained it for long intervals after learning. A: acquisition curves for trace conditioned, pseudoconditioned, and slow-learning rabbits, and retention curves for trace-conditioned rabbits. Conditioned eye-blink was stably asymptotic when tested at intervals $\leq 180$ days after initial acquisition. Acquisition curves represent normalized data from all subjects, whereas retention curves are for small subset of subjects used exclusively for retention testing. $B$ : percentage of conditioned responses (CRs) in 1st and last training sessions for all control and conditioned rabbits used for analyses of hippocampal CA3 excitability. Only trace conditioning resulted in an increase in CRs above behavioral criterion for acquisition. $C$ : percentage of CRs for subjects dually tested for long-term retention (i.e., both behavioral and neurophysiological data was collected from this group). Again, training resulted in an increase in CRs that was maintained after reaching criterion, without intervening training. Behavioral criterion of $80 \% \mathrm{CRs}$ is shown $(---)$ in all panels.

tude, duration, and area was not significantly different if calculated for individual cells, either as an average per slice if two cells were recorded from the same slice or an average of all cells recorded (an average of 2.6 CA3 neurons each) from the same rabbit $(P>0.7)$. This concurs with similar findings of reliably small variance within samples from the same behavioral conditions in CA1 pyramidal neurons from the same rabbit population (Moyer et al. 1996). As in CA1 (deJonge et al. 1990), AHP amplitude was related directly to the number of spikes per burst (i.e., increased with increased number of spikes evoked per burst) and was slightly influenced by current clamping the membrane potential 2-5 $\mathrm{mV}$ more hyper- or depolarized than the resting potential. Postburst AHPs in C.A3 neurons were nearly $250 \%$ larger in amplitude and $290 \%$ longer in duration than those in CA1 neurons from the same naive rabbits (Moyer et al. 1996). These large AHPs in CA3 neurons were accompanied by robust spike-frequency accommodation. The same 100-ms depolarizing current pulse used to evoke a four-spike AHP, when prolonged for $800 \mathrm{~ms}$, produced only $4.12 \pm 0.04$ spikes in CA3, evidence of very potent accommodation. With their smaller postburst AHPs, CA1 neurons from the same rabbits exhibited nearly $37 \%$ more spikes per burst during accommodation testing (Moyer et al. 1996). As seen in Fig. 3B, a "sag', typically occurred in the voltage response of CA3 neurons during depolarizing current injection. This sag was unlikely to be related to the sag current, $I_{\mathrm{Q}}$, which 


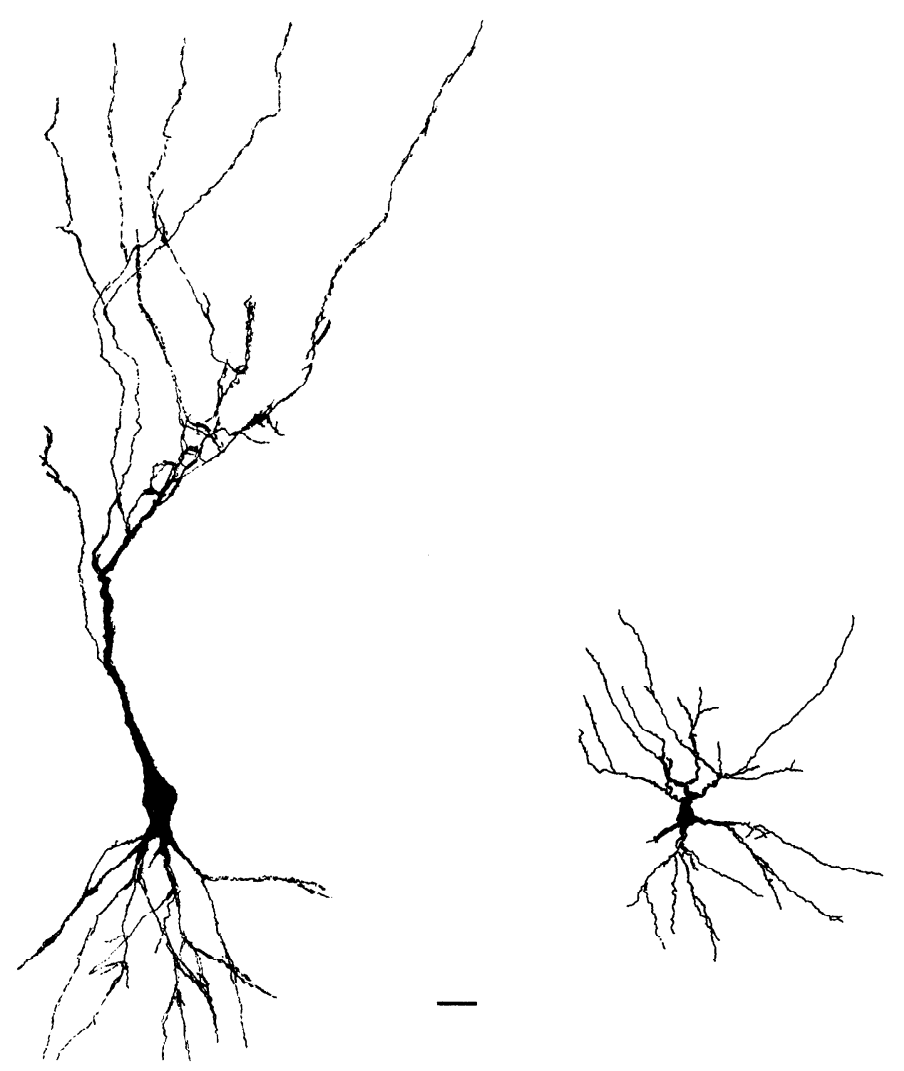

FIG. 2. Camera lucida drawings of a representative CA3 pyramidal neuron and a CA3 basket cell, filled with neurobiotin during recording in area CA3a stratum pyramidale. Differences in size, dendritic branching, and physiological characteristics of these cell types made discrimination between 2 reliable. Only a small sample of interneurons, including basket cells, was obtained, and no systematic analysis of learning-related changes was attempted. Scale bar is $20 \mu \mathrm{m}$.

is activated by hyperpolarizing current pulses (Colino and Halliwell 1994). Instead, this hyperpolarizing response during depolarizing current injection is indicative of the tight clamp on excitability imposed by the AHP after the firing of each action potential by CA3 ncurons.

\section{Trace conditioning enhanced CA3 pyramidal cell excitability}

Acquisition of the 500-ms trace-conditioned eye-blink greatly enhanced C.A3 pyramidal neuron excitability (see Figs. 3 and 4). The postburst AHPs of CA3 pyramidal neurons were reduced significantly $\left(F_{9,191}=36.6, P<0.001\right)$ $24 \mathrm{~h}$ after successful acquisition of the hippocampally dependent task, a finding that concurs with those observed in CA1 pyramidal cells from trained rabbits (Disterhoft et al. 1986; Moyer et al. 1996). Not only the amplitude, but also the duration $\left(F_{9,191}=14.3, P<0.001\right)$ and the integrated area $\left(F_{9,191}=10.8, P<0.001\right)$ of the postburst AHP were significantly reduced after learning. Table 1 summarizes changes in the duration of the AHP in CA3 neurons after successful acquisition of the trace conditioned eyeblink response, in comparison with controls.

Spike-frequency adaptation $24 \mathrm{~h}$ after learning also was reduced shortly after learning $\left(F_{9,191}=10.59, P<0.001\right)$. Such a reduction was not previously seen after acquisition of other eye-blink conditioning paradigms (delay or trace $300 \mathrm{~ms}$ ) that are not characterized as hippocampally dependent (Akase et al. 1989; Moyer et al. 1990; Schmaltz and Theios 1972). Reduced accommodation also was observed, however, for CA1 pyramidal neurons after hippocampally dependent trace 500 conditioning (Moyer et al. 1996). Reductions in both the AHP and in accommodation specifically increased CA3 excitability. As mentioned above, AHP measures for $\mathrm{CA} 3$ neurons from behaviorally naive rabbits were distributed normally (see Fig. $4 B$ ), whereas accommodation measures were not (see Fig. 4D). Consequently, the definition of a significant reduction in either measure was selected to allow for nonnormal distributions.

Changes in the mean values of these two excitability measures tell very little about the number of neurons actually exhibiting excitability changes, because a large change in a small subset of the population could greatly skew the group mean. As seen in Fig. 4B, AHP measures for neurons from behaviorally naive controls fit a normal distribution (i.e., $>99 \%$ of the population fell within 2 SD of the control mean, more than the predicted $95.4 \%$ of a normally distributed population that would lie within these limits). Figure $4 D$ shows that accommodation measures were not normally distributed (using the methods defined, no fewer than 4 spikes per burst were possible). Tchebycheff's theorem (Kirk 1978) indicates that even for nonnormal distributions, $>88.8 \%$ of a given population fall within $3 \mathrm{SD}$ of the mean for that population, whereas for normally distributed populations, $>99.7 \%$ of the population fall within $3 \mathrm{SD}$ of the mean. Therefore, very conservative definitions allowing for nonnormal distributions were used to define learning-specific effects as an increase in the number of spikes elicited during accommodation or a decrease in AHP amplitude $>3$ SD from the mean observed for behaviorally naive controls. This allowed direct comparisons to be made between changes in the AHP and changes in accommodation.

Figure $5 \mathrm{~A}$ shows that more than half of all $\mathrm{CA} 3$ pyramidal neurons exhibited significantly reduced AHPs soon after acquiring the trace-conditioned eye-blink task. A significant number $(45 \%)$ of CA3 neurons also showed reduced accommodation (see Fig. 5B), reflecting the potent influence of the significantly reduced but still large AHP, even after learning (see Fig. 3). Both findings are convergent with similar proportions of learning-related changes in CA1 neurons from the same rabbits (Moyer et al. 1996). The percentage of CA3 neurons exhibiting these reductions then decayed over time as described below. Even those CA3 neurons that failed to meet conservative criterion for increased excitability tended to exhibit small reductions in the AHP, in accommodation, or in both measures (data not shown). None exhibited increases in these measures after learning. Given that the changes were limited in sign as well as type, this suggests that a limited set of conductances changed after learning (see also Sanchez-Andres and Alkon 1991). A number of other biophysical measures in CA3, including input resistance $\left(F_{9,191}=0.7, P>0.6\right)$, sag $\left(F_{9,191}=2.1, P>0.1\right)$, current required to evoke a four-spike burst $\left(F_{9,191}=0.4\right.$, $P>0.5)$, action potential spike height $\left(F_{9,191}=1.3, P>\right.$ $0.2)$ or width $\left(F_{9.191}=1.1, P>0.3\right)$, and membrane resting potential $\left(F_{9,191}=1.3, P>0.2\right)$ were unaffected by training. 


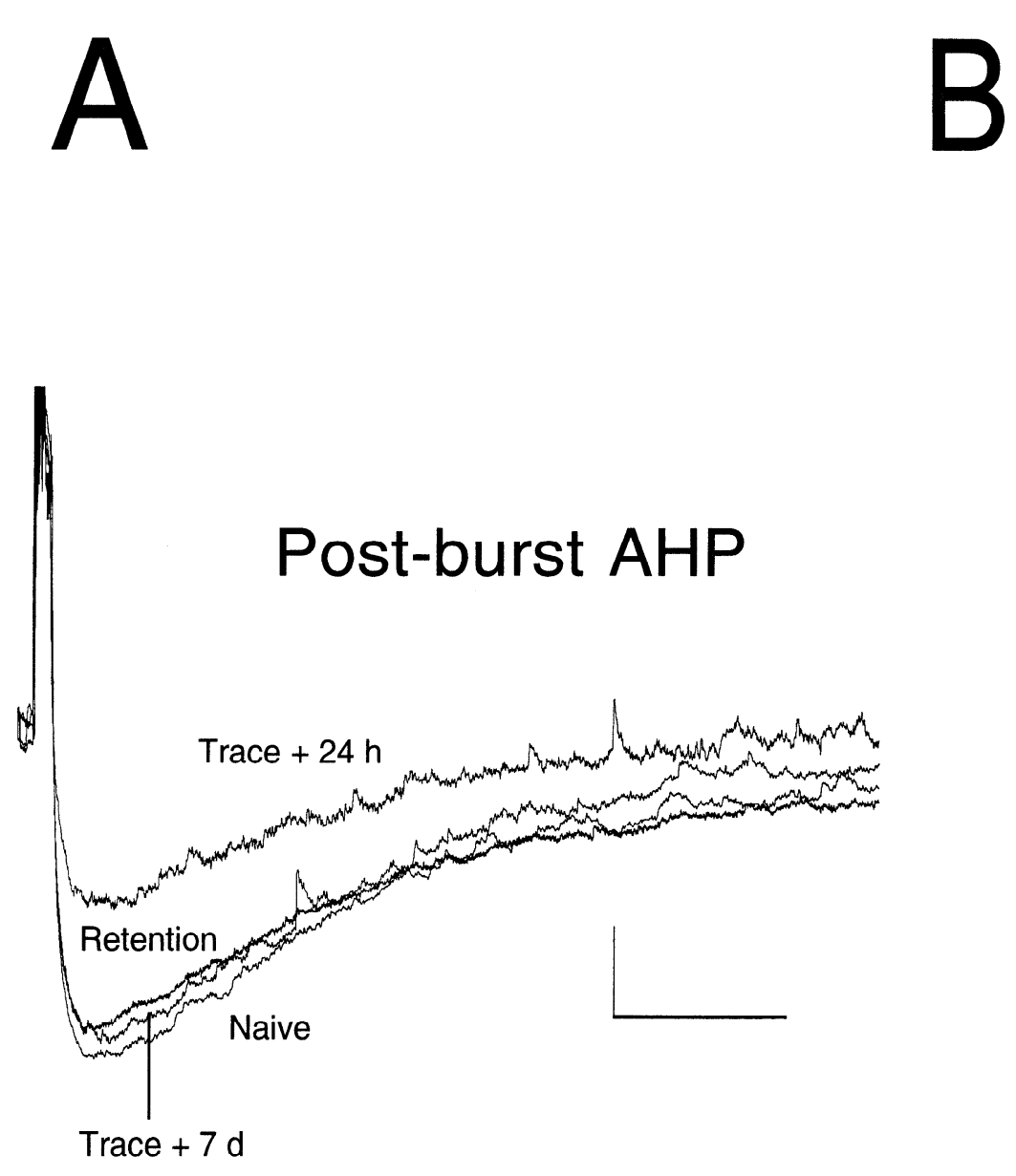

\section{Accommodation}
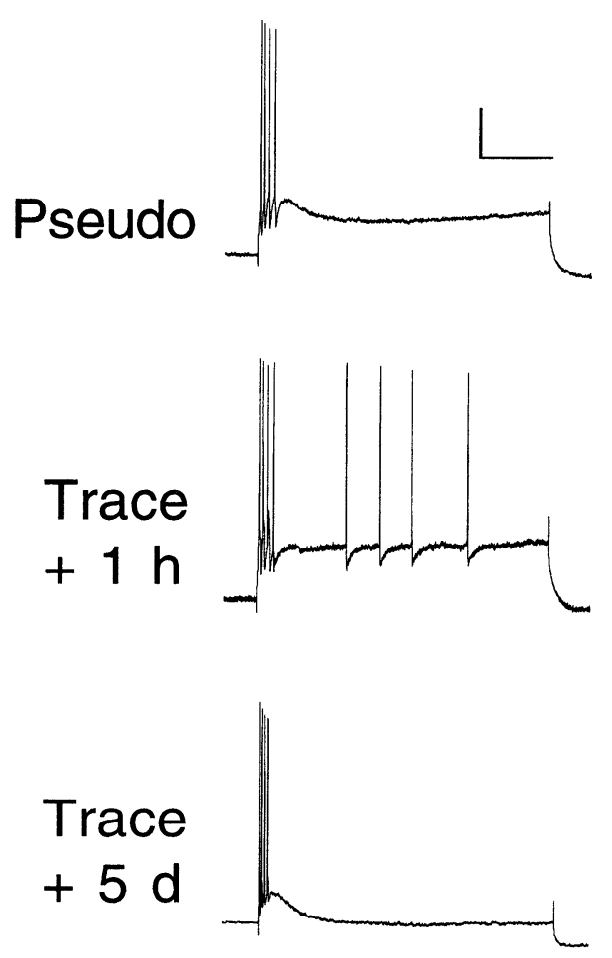

Retention

FIG. 3. Both postburst afterhyperpolarization (AHP) and spike-frequency accommodation were altered time dependently by learning. $A$ : neurons from naive or pseudoconditioned controls exhibited large-amplitude AHPs of long duration. Both amplitude and duration of AHP were reduced soon after acquisition, then returned to naive-like basal levels during a 7-day period. Long-term retention testing did not reinstate reductions in AHP. Waveforms are overlaid from neurons with identical resting potentials that approximated mean values for groups shown. $B$ : accommodation was robust in neurons from control rabbits, but was reduced greatly in neurons in slices prepared soon after learning. Accommodation also returned to naivelike basal levels in a time-dependent manner, with an earlier time coursc, and was unaffected by retention testing. Scale bars are $5 \mathrm{mV}$ and $1 \mathrm{~s}$ in $A, 20 \mathrm{mV}$ and $200 \mathrm{~ms}$ in $B$.

Table 2 lists unchanged biophysical measures for all groups tested.

\section{Enhanced pyramidal cell excitability was transient}

Both measures that contribute to enhanced excitability only were affected transiently by learning. Reductions in the postburst AHP were maximal at intervals from 1 to $24 \mathrm{~h}$ after rabbits reached behavioral criterion in the conditioning task (see Fig. 4), as were reductions in accommodation. The two effects then decayed with different time courses, with the AHP significantly reduced $(P<0.001)$ compared with all control groups at intervals $\leq 5$ days after learning, whereas accommodation returned to a naive-like state within 3 days. At intervals of 7 or 14 days after learning, excitability was similar to that observed in cells from untrained animals (see Fig. $6 ; P>0.7$ ). A similar time-course of transient changes in excitability postconditioning was observed in CA1 neurons (Moyer et al. 1996). The changes in both CA1 and CA3 hippocampal pyramidal cell populations roughly parallels the narrow time window observed in behavioral studies of memory consolidation, in which ablation or reversible blockade of the hippocampus blocked long-term retention of a learned task only relatively soon after acquisition, and had no effect at longer time intervals (Kim and Faneslow 1992; Kim et al. 1995). The duration of this time window for consolidation appears to vary dependent upon the task and its specifics as well as upon the species studied (Bloch 1970; Cohen and Eichenbaum 1993; McGaugh 1966; Squire 1987). The time course of decay in the proportion of CA3 cells with decreased AHPs (Fig. 5) was similar to the decay in the mean amplitude of the AHP (Fig. 4). The time course of the decay in CA3 neurons exhibiting reduced accommodation was more rapid, whether measured in terms 
A
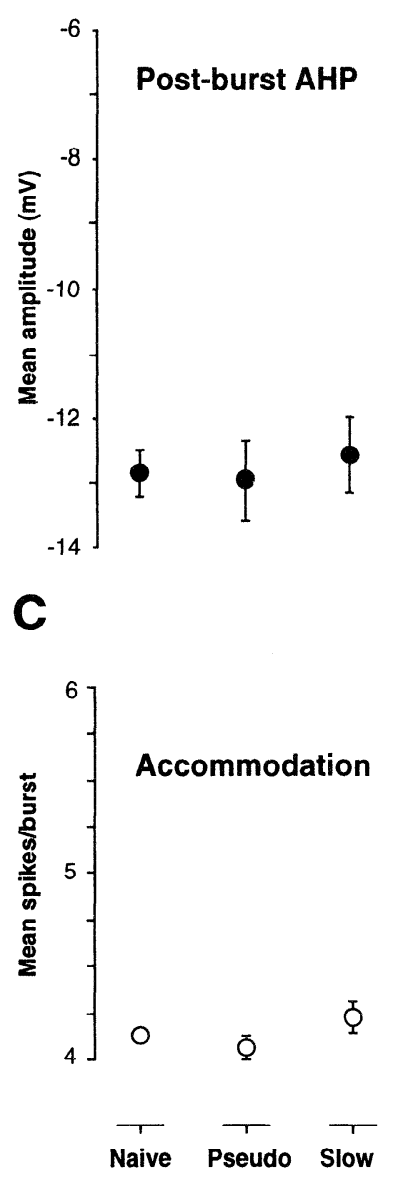
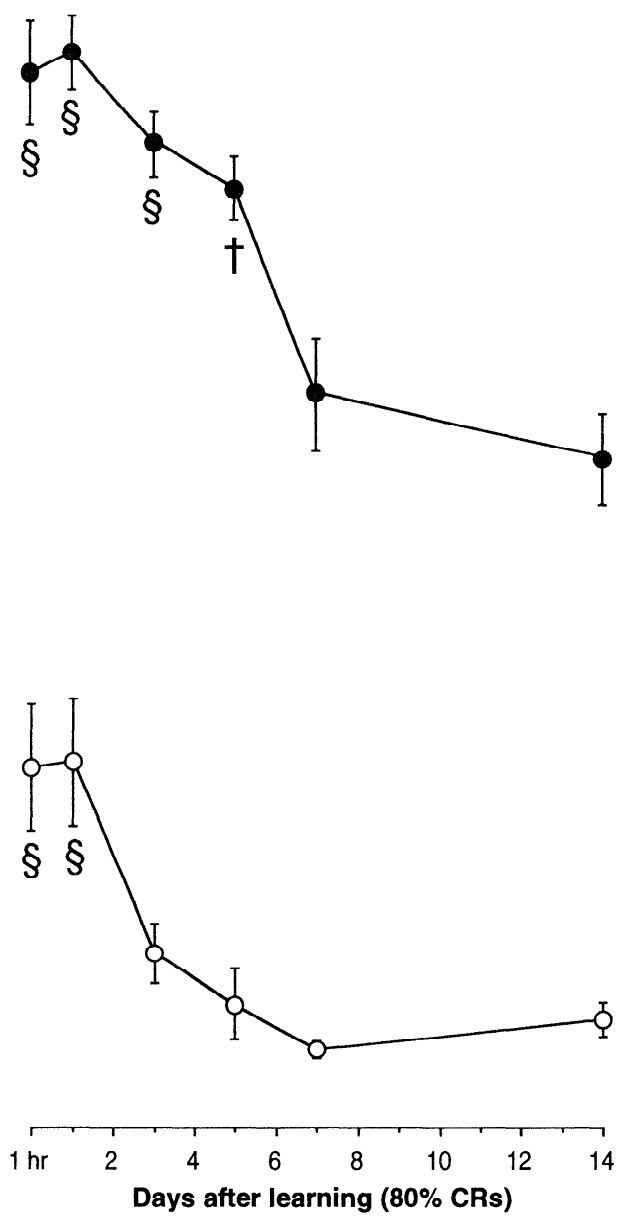

B
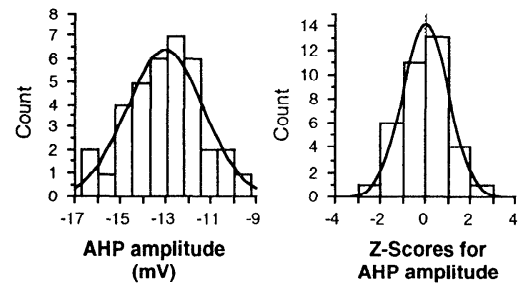

D
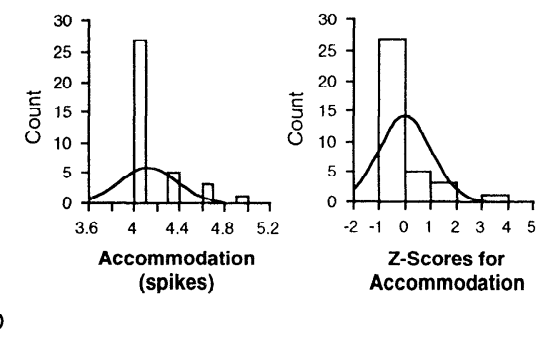

FIG. 4. Magnitude of AHP and of accommodation are plotted over time after learning in comparison to controls. A: mean amplitude $( \pm$ SE) of postburst AHP was reduced significantly soon after learning, then decayed with a time course of 7 days back to large-amplitude basal lcvel that was observed in naive, pseudoconditioned (Pseudo), and slow-learning (Slow) controls. Explicit retention testing (Retention) did not result in reductions of the AHP from naive or basal levels. $\$ P<$ $0.001 ; \dagger P<0.001$ from all control groups. $B$ : AHP amplitudes were distributed normally for neurons in slices prepared from behaviorally naive controls. Normal distributions are overlaid on distributions of AHP amplitudes and $Z$ score for AHP amplitudes. Similar and overlapping distributions were obtained for other control groups (data not shown). $C$ : mean number of spikes during accommodation testing was increased significantly after soon after learning and decayed with a more rapid time course of 3 days to levels observed in controls. Again, retention testing did not reinstate learning-related changes in accommodation. $\S P<0.001$ from all control groups. $D$ : accommodation measures were not normally distributed, due in part to methods used for testing and in part to extremely robust accommodation present in CA3 pyramidal neurons from behaviorally naive controls. As a consequence, tests for changes in excitability shown in Fig. 5 used definitions allowing for nonnormal distributions.

of mean values (Fig. 4) or percentage of cells changed (Fig. 5).

\section{Changes in excitability were learning specific}

The effects observed on CA3 excitability were learning specific. CA3 neurons from pseudoconditioned rabbits were no more excitable than those from naive controls (see Figs. 4 and 5; $P>0.9$ ). Similarly, no excitability changes were seen in neurons from slow-learning rabbits $(P>0.9)$. This finding cxtends an carlier report that neurons from slow learners in delay conditioning showed no learning-specific changes in excitability (Disterhoft et al. 1988).

A more explicit test of the dissociation of excitability changes from behavioral performance also was carried out in the current study. When performance of the learned re- sponse was tested 14 days after initial acquisition, using explicit pairing of the CS-US stimuli as in the initial behavioral training, behavioral performance was fully asymptotic. The excitability of CA3 pyramidal neurons recorded $24 \mathrm{~h}$ after retention testing, however, was indistinguishable from that of controls $(P>0.9)$. All AHP measures and accommodation in this retention group were indistinguishable from those observed in the basal naive state. Behavioral retesting thus did not alter the decay of excitability back to basal levels. As seen in Fig. 1, retention of the eyeblink response was asymptotic at intervals 7 and 14 days and far longer after learning. As noted, CA3 neurons in slices prepared from rabbits that had acquired the task 7 or 14 days previously were indistinguishable from those of behaviorally naive controls. In fact, behavioral retention of the conditioned eye-blink task persisted for intervals more than an 
TABLE 1. Summary of learning-specific changes in duration of the postburst afterhyperpolarization in CA3 pyramidal neurons

\begin{tabular}{lrrrr}
\hline \hline & & \multicolumn{2}{c}{ Postburst AHP } \\
\cline { 3 - 4 } \multicolumn{1}{c}{ Group } & $n$ & Duration, ms & Area, mVms & $n$ \\
\hline Naive & 15 & $9,109 \pm 121$ & $-26,926 \pm 414$ & 36 \\
Pseudo & 12 & $9,214 \pm 142$ & $-27,199 \pm 390$ & 25 \\
Slow & 3 & $9,193 \pm 89$ & $-27,119 \pm 443$ & 9 \\
Trace 1 hr & 8 & $6,215 \pm 221^{*}$ & $-15,910 \pm 488^{*}$ & 22 \\
Trace 24 hr & 9 & $6,148 \pm 209^{*}$ & $-16,298 \pm 521^{*}$ & 24 \\
Trace 3 day & 7 & $7,197 \pm 311 \dagger$ & $-20,776 \pm 507 \dagger$ & 18 \\
Trace 5 day & 7 & $8,204 \pm 251 \neq$ & $-23,873 \pm 511 \neq$ & 17 \\
Trace 7 day & 7 & $8,761 \pm 227$ & $-25,582 \pm 476$ & 19 \\
Trace 14 day & 6 & $9,031 \pm 143$ & $-27,193 \pm 487$ & 21 \\
Retention & 4 & $9,094 \pm 303$ & $-27,645 \pm 492$ & 10 \\
\hline
\end{tabular}

Values are means \pm SE. The 1 st $n$ are for rabbits; the 2 nd $n$ is for cells. A 100-ms depolarizing current pulse minimally sufficient to evoke a burst of 4 action potentials within this interval was used, and the resultant after hyperpolarization (AHP) was measured from current offset until return to resting potential for a minimum of $10 \mathrm{~ms}$. Integrated area was calculated from current offset for the entire AHP duration. Significantly different from all control groups (naive, pseudoconditioned, and slow learners): $* P<$ $0.001 ; \dagger P<0.01 ; \uparrow P<0.05$.

order of magnitude longer than the observed changes in hippocampal excitability, whether in CA3 as here or in CA1 (Moyer et al. 1996). This indicates that the excitability changes observed in CA3 or in CA1 were not required to support long-term memory of the learned task.

\section{IS C US SION}

Large and significant reductions of both the postburst AHP and of accommodation were observed in CA3 neurons 1$24 \mathrm{~h}$ after reaching behavioral criterion in the hippocampally dependent trace eye-blink conditioning task. The effects of learning decayed fairly rapidly with progressively less excitability observed 3 or 5 days after criterion was reached and a full return to naive baseline levels after 7 days. The effects of learning were restricted to these measures as others including input resistance, resting potential, and action potential height or width were unaffected.

The effects observed were also highly learning specific. Pseudoconditioning, using the same tone and airpuff stimuli but in a nonassociative fashion, had no effect on neuronal excitability, indicating a lack of sensitization from the stimuli alone and a lack of effect of performance of equal numbers of nonassociative eyeblink responses. This finding is consistent with earlier results, both from studies of postacquisition in vitro excitability in CAI (Coulter et al. 1989; de Jonge et al. 1990; Disterhoft et al. 1986, 1988) and from earlier extracellular single- and multiple-neuron recording studies in CA1 and CA3 in vivo after eyeblink conditioning: pseudoconditioning had no effects on hippocampal pyramidal cell excitability or at least none measurable after repeated training. In an extension and conceptual replication of earlier findings (Disterhoft et al. 1988), CA3 pyramidal neurons from the small subset of slow-learning rabbits that had undergone training with associatively paired stimuli but failed to exhibit performance $>30 \%$ CRs even after 15 training

A
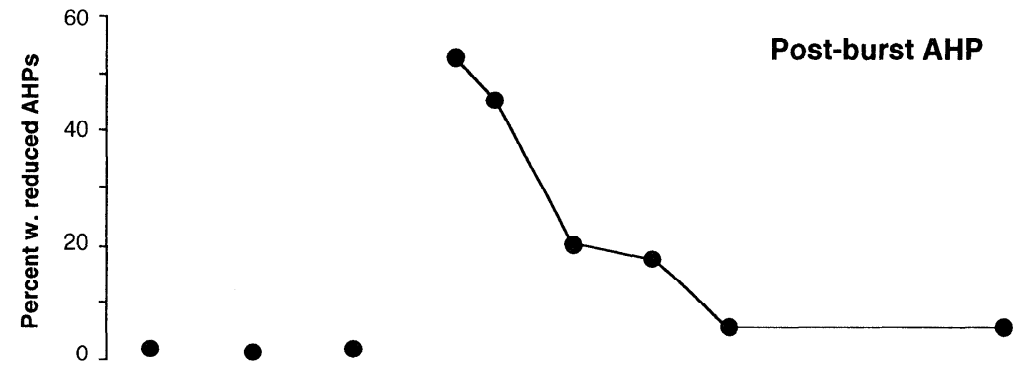

B

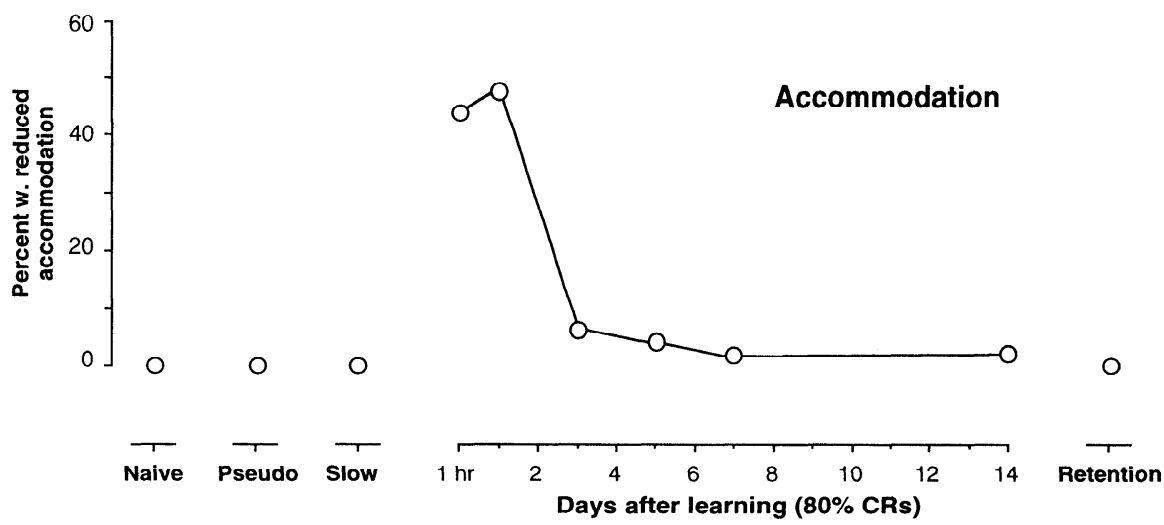

FIG. 5. A sizeable fraction of all CA3 pyramidal neurons tested exhibited learning-specific changes in excitability soon after learning. A: percentage of neurons with reduced AHPs decayed with a time course similar to that observed in mean values plotted in Fig. 4. B: similarly, percentage of neurons with reduced accommodation decayed with a more rapid time course, similar to that observed in mean values plotted in Fig. 4. Retention testing did not induce excitability changes outside naive range in even a small percentage of neurons. 
TABLE 2. Summary of membrane properties that do not change with learning in CA3 pyramidal neurons

\begin{tabular}{|c|c|c|c|c|c|}
\hline \multirow[b]{2}{*}{ Group } & \multirow{2}{*}{$\begin{array}{c}\text { Input } \\
\text { Resistances, } \\
\mathrm{m} \Omega\end{array}$} & \multirow{2}{*}{$\begin{array}{c}\text { Sag } \\
\text { Amplitudes, } \\
\mathrm{mV}\end{array}$} & \multicolumn{2}{|c|}{ Action Potential } & \multirow{2}{*}{$\begin{array}{l}\text { Resting } \\
\text { Potentials, } \\
\text { mV }\end{array}$} \\
\hline & & & Amplitudes, mV & Widths, ms & \\
\hline Naive & $48.3 \pm 2.0$ & $9.3 \pm 1.2$ & $93.6 \pm 0.9$ & $1.4 \pm 0.08$ & $-66.6 \pm 0.4$ \\
\hline Pseudo & $47.6+2.5$ & $8.7 \pm 1.9$ & $95.2 \pm 1.6$ & $1.3 \pm 0.11$ & $-67.0 \pm 0.7$ \\
\hline Slow & $47.1 \pm 2.7$ & $9.2 \pm 1.7$ & $94.3 \pm 1.2$ & $1.4 \pm 0.09$ & $-66.8 \pm 0.6$ \\
\hline Trace $1 \mathrm{~h}$ & $46.9 \pm 3.4$ & $8.6 \pm 2.1$ & $95.2 \pm 0.8$ & $1.4 \pm 0.08$ & $-66.9 \pm 0.5$ \\
\hline Trace $24 \mathrm{~h}$ & $43.4 \pm 2.5$ & $8.7 \pm 1.1$ & $96.6 \pm 1.3$ & $1.4 \pm 0.05$ & $-67.6 \pm 0.7$ \\
\hline Trace $3 \mathrm{~d}$ & $46.5 \pm 1.7$ & $8.9 \pm 1.4$ & $94.4 \pm 1.4$ & $1.3 \pm 0.12$ & $-68.2 \pm 0.6$ \\
\hline Trace $5 \mathrm{~d}$ & $45.1 \pm 2.2$ & $9.0 \pm 0.9$ & $93.2 \pm 1.3$ & $1.4 \pm 0.11$ & $-68.2 \pm 0.5$ \\
\hline Trace $7 \mathrm{~d}$ & $47.0 \pm 2.6$ & $8.4 \pm 1.8$ & $97.9 \pm 1.2$ & $1.3 \pm 0.09$ & $-66.8 \pm 0.5$ \\
\hline Trace $14 \mathrm{~d}$ & $47.4 \pm 1.8$ & $8.0 \pm 1.7$ & $96.8 \pm 1.0$ & $1.4 \pm 0.07$ & $-67.1 \pm 0.5$ \\
\hline Retention & $51.5 \pm 3.3$ & $8.9 \pm 1.5$ & $97.1 \pm 1.3$ & $1.4 \pm 0.10$ & \pm 0.6 \\
\hline
\end{tabular}

Values are means $\pm \mathrm{SE}$. Input resistance was calculated from the plateau voltage response during the final $75 \mathrm{~ms}$ of a 400 -ms $0.2 \mathrm{nA}$ hyperpolarizing pulse. The depolarizing sag was calculated as the potential difference between the peak negative amplitude and the plateau potential in response to a 1.0 nA 400 ms hyperpolarizing current pulse. Action potential measures were determined for singlc action potentials, with amplitude measured from rest, and spike width at one-third peak amplitude. Resting potential was the potential difference before and after withdrawing the microelectrode from the cell, with no holding current.

sessions (1,200 trials) also failed to show learning-specific changes in excitability on either the postburst AHP or spike frequency accommodation measure. Finally, neuronal excitability returned to basal levels within a limited period after learning occurred rather than remaining high for an indeterminate period.

Long-term memory of the trace-conditioned eye-blink task was independent of hippocampal excitability as rabbits tested at intervals up to 6 mo later exhibited $>80 \%$ CRs per retention session (see Fig. 1). Even neurons from slices prepared $24 \mathrm{~h}$ after sessions in which rabbits were presented with a full conditioning session (see Retention controls, Fig. 4, and compare also with 14-day time point) were indistinguishable from naive controls, again dissociating excitability changes in the hippocampus from memory or performance of the eye-blink task at intervals after consolidation of the learned response had occurred. The changes observed thus were highly specific to acquisition or to consolidation of the conditioned response and not to its performance nor to its long-term memory. The evidence indicating that during a critical period postacquisition the hippocampus is required for consolidation of the trace-conditioned eye-blink into a long-term memory ( see Kim et al. 1995) is discussed below.

The changes observed were localized wholly both to the hippocampus and to the postsynaptic CA3 neurons studied here by virtue of the in vitro preparation used ( see Disterhoft et al. 1986). No afferent synaptic stimuli were required at the time of observation of the increased excitability. In fact, earlier studies that specifically blocked synaptic transmission in the hippocampal slice (Coulter et al. 1989) demonstrated reliable learning-specific increases in postsynaptic excitability (evoked by intracellular current injection) after acquisition of eye-blink conditioning. These and earlier findings do not rule out changes in synaptic transmission initiating the observed postsynaptic plasticity. A number of neurotransmitters have been shown to modulate the postburst AHP (Benardo and Prince 1982; Colino and Halliwell 1987; Haas and Greene 1984; Haas and Konnerth 1983; Hedlund and Andersen 1989; Liu et al. 1993; Madison and Nicoll 1986b; Malenka and Nicoll 1986), and the one(s) initiating the learning-specific changes observed here remain to be determined. Notably, cholinergic agonists reduce the AHP and accommodation of pyramidal neurons in hippocampal slices (Cole and Nicoll 1983, 1984; Knöpfel et al. 1990), whereas cholinergic antagonists impair learning in many tasks, including eye-blink conditioning (Harvey et al. 1985; Solomon et al. 1983). Hasselmo (Hasselmo 1995; Hasselmo and Schnell 1994) has modeled extensive network properties associated with theoretical and observed models of learning and included important roles both for alterations in cholinergic transmission and for changes in the postburst AHP and in spike-frequency accommodation of pyramidal neurons.

Increased excitability has important theoretical and functional consequences. Reductions in spike frequency accommodation (whether directly or indirectly mediated by reductions in the postburst AHP) make CA3 neurons more likely to fire more action potentials in response to an excitatory afferent stimulus. In effect, both types of learning-specific changes observed would tend to amplify excitatory throughput via the hippocampal circuitry for a transient period after learning and might act in concert with the (hypothetical) synaptic plasticity frequently presumed to occur in vertebrate learning. Weakly enhanced afferent signals thus could be amplified and perhaps stabilized for a critical time period. More strongly enhanced afferents would be amplified still more, perhaps providing a necessary increase in signalto-noise ratio to a site efferent to the hippocampus. It should be noted that excitability was not radically altered by learning (i.e., not even a small proportion of neurons became epileptiform), but rather it was modulated within a range averaging half of its basal state. Also neurons returned to a naive-like state within a week after training, again fully ready to exhibit either the same or different constellations of changes as demanded by the behavioral requirements of the organism. Behavioral studies by Kim et al. (1995) in the same behavioral preparation, trace eye-blink conditioning, as wcll as numerous studies in other preparations exhibiting some degree of hippocampal dependence (Hampson et al. 1993; Kim and Faneslow 1992; Zola-Morgan et al. 1989) have revealed a critical time-limited period postacquisition 
in which hippocampal functional integrity is required for retention and long-term storage of new learned behaviors. The changes observed in the present study appear to meet the requirements for a sustained functional change in the hippocampus during the period in which memory consolidation (Cohen and Eichenbaum 1993; McGaugh 1966) occurs. Once consolidation is complcte, and the representation of the memory - the "engram" - is laid down in (an) extrahippocampal locale(s), increased excitability is no longer needed and excitability thus returns to basal levels. The current findings thus corroborate and extend earlier data from in vivo (e.g., Berger et al. 1983) and in vitro (e.g., Disterhoft et al. 1986) studies that showed learning-related changes in hippocampal excitability during or shortly after acquisition.

Byrne (1987) listed six criteria for identifying necessary, sufficient, and exclusive properties of neuronal elements supporting learning and memory. Byrne's second criterion, which applies to the current findings, was that the time course of changes in neuronal properties should match the time course of a specific phase of learning. The data presented here, in conjunction with other findings cited, meet this criterion and demonstrate a relation between consolidation of the learned response and changes in hippocampal excitability. Other criteria for hippocampal learning specificity according to Byrne's criteria that also are met by the current and by earlier findings include: neural correlates during learning (Berger et al. 1976, 1983; Solomon et al. 1986); lack of learning-specific changes in the absence of learning (Disterhoft et al. 1988 and the present findings); and ablation of the learned response by ablation of the structure (Kim et al. 1995; Moyer et al. 1990; Solomon et al. 1986). Two final criteria remain. The first, determining whether blocking learning-specific cellular changes would block learning, remains to be directly tested in the trace eye-blink model. However, the converse is true, at least in aging rabbits, which exhibit enhanced AHPs compared with young behaviorally naive rabbits (Moyer et al. 1992). In vitro, the dihydropyridine $\mathrm{Ca}^{2+}$ channel antagonist nimodipine blocks $\mathrm{Ca}^{2+}$ influx via L-type channels in hippocampal pyramidal neurons (Moyer et al. 1996), reduces the plateau phase of the calcium action-potential in these neurons (Moyer and Disterhoft 1994), and, most relevant to the current study, dose dependently reduces the amplitude and duration of the calcium-dependent AHP in hippocampal slices (Moyer et al. 1992). Nimodipine increases basal firing rates of rabbit hippocampal pyramidal neurons in vivo (Thompson et al. 1990) and significantly improves the eye-blink conditioning acquisition rates of aging-impaired rabbits (Deyo et al. 1989).

Byrne listed one additional final criterion: whether the magnitude of the learning-specific changes models the magnitude of the learning. A considerable fraction $(>50 \%$ for AHPs and $45 \%$ for accommodation) of all neurons tested exhibited learning-specific changes in postsynaptic excitability soon after learning. Although these percentages declined over time, with the neurons tested 7-14 days after learning indistinguishable from naive controls, the question must be addressed as to why such a large number of neurons exhibited such a significant change. Observations of large numbers of neurons changing in response to external or behavioral events are not novel but are certainly striking and require further analysis. For example, ensembles of relatively large numbers of hippocampal ncurons are activated during and after learning of complex spatial tasks (Breese et al. 1989; Eichenbaum et al. 1989a,b; Mizumori et al. 1989; Thompson and Best 1989), during slow-wave sleep (Olmstead et al. 1973), and during the theta rhythm (Buzsáki 1989). The present situation presented the rabbits with only one salient behavioral association to acquire, whereas other aspects of their existence purposefully were made uniform as compared with those experienced in their native environments. Whether varying the behavioral salience would diminish the magnitude of the observed effect on neuronal excitability and whether a greater total effect would result from conditioning in multiple tasks remains to be determined. As noted, the changes observed were not extreme and did not approach total elimination of the AHP or of accommodation. Considerable potential plasticity still could occur in both the postburst AHP and in spike frequency accommodation in the cells that exhibited learning-specific changes. Alternately, a still larger fraction (or differing subpopulations) of the total neuronal population could exhibit the same magnitude of changes, all without saturating the capacity of the system. Our demonstration of excitability changes in a specific restricted learning paradigm does not preclude any of these possibilities nor does it imply that the quantitative changes observed accurately reflect the quantitative changes that might be expected in other situations. The specific pattern of changes (i.e., which particular neurons within the network of all hippocampal neurons will exhibit altered excitability after learning a given task) remains to be deciphered with other techniques. Further, the lack of any apparent change in input resistance should not be taken as definitive due to the fact that the methods used for this measurement (evaluating voltage responses to membrane hyperpolarizations) do not meet the necessary conditions (activation of voltage-gated $\mathrm{Ca}^{2+}$ channels) required for activation of the calcium-dependent AHP. What is apparent, however, is that changes in membrane excitability appear to be a basic conserved mechanism of learning-specific plasticity, from invertebrates (Alkon 1984; Carew and Sahley 1986; Klein and Kandel 1978; Scholz and Byrne 1987) to vertebrates (Disterhoft et al. 1994; Sanchez-Andres and Alkon 1991; Woody et al. 1991) and that altering $\mathrm{K}^{+}$conductances may be a preferred mechanism.

The time course of changes in the AHP and in accommodation diverged somewhat, with accommodation returning to basal levels several days before the AHP returning to full basal amplitude and duration. The mechanisms contributing to the time-dependent decay in excitability are presently unknown and will require further study. However, such a temporal limitation would seem a basic requirement of any system evolved to learn multiple tasks without quickly saturating, reaching a point at which no further plasticity (and thus no new learning) could occur. Although clearly related, the linkages between plasticity in the postburst AHP and in spike-frequency adaptation or accommodation are correlational and not fully defined in the literature (e.g., Madison and Nicoll 1986a; Moyer et al. 1992). These linkages require further study, particularly within the context of associative learning.

As noted earlier, the findings of the current study were obtained in conjunction with a parallel study of time-depen- 
dent learning-specific excitability changes in CA1 pyramidal neurons (Moyer et al. 1996). As in CA3, increased excitability was evident (in terms both of reduced AHPs and of reduced accommodation) soon after learning. In CA1, excitability increases were maximal $24 \mathrm{~h}$ after acquisition of the trace eye-blink response. Both AHPs and accommodation in CA1 returned to naive basal levels after 7 days, whereas in CA3, accommodation returned to basal levels somewhat more rapidly. In both hippocampal regions, neurons from behavioral controls (including pseudoconditioned, slowlearning, and retention or performance controls) were indistinguishable from neurons from behaviorally naive subjects, in spite of repeated stimulus presentation and eyeblink response performance. These similarities between rabbit CA1 and CA3 regions after eye-blink conditioning are consistent with earlier data from extracellular single- and multipleunit recordings in vivo (Berger et al. 1983) showing similar learning-specific increases in neural modeling of the conditioned response in both hippocampal subfields and distinguish pyramidal cell responses from the lack of response of granule cells late in learning ( see also de Jonge et al. 1990). The absolute magnitude of the learning-specific AHP changes observed in region CA1 were smaller than those observed in CA3 but were of the same relative magnitude when scaled to the smaller magnitude of naive CA1 AHPs. Similarly, the absolute magnitude of CA3 accommodation changes were smaller than those for CA1 but comparable when scaled to compensate for differing naive states in the two hippocampal subfields. In both regions, approximately half of all neurons tested exhibited learning-specific changes in in vitro excitability soon after rabbits successfully acquired the hippocampally dependent trace-conditioned eyeblink task. In both regions, the learning-specific changes were time dependent and decayed to the naive state after learning consolidation was complete. More sophisticated studies (using voltage-clamp and intradendritic recording protocols) of neuronal membrane properties electrotonically distal from the neuronal soma are needed to demonstrate the generality of the current findings and are planned for the future. Several studies have argued that initial events, occurring soon after learning in the soma of hippocampal neurons, are transferred with time to the dendrites and no longer present in the soma (Bank et al. 1988; Olds et al. 1989). The results of Kim et al. (1995), however, indicate that hippocampal function is no longer required $1 \mathrm{mo}$ after trace conditioning. In the current study, asymptotic behavioral performance endured for time periods more than an order of magnitude longer than the observed enhancement of hippocampal excitability.

These data indicate that hippocampal excitability is altered during and for a short period after some forms of associative learning (and may contribute to induction of the engram in extra-hippocampal brain regions), but that sustained changes in the excitability of hippocampal neurons are not required for long-term memory of the learned behavior. A dissociation between some mechanisms of learning consolidation and of long-term memory thus may be found at the cellular level in the in vitro mammalian hippocampus.

This research was supported by National Institutes of Health Grants 1 R01 DA-07633, 1 R01 MH-47340, and 1 R01 AG-08796.
Address for reprint requests: L. T. Thompson, Dept. of CM Biology, Northwestern University Medical School, Searle 4-441, 303 E. Chicago Ave., Chicago, IL 60611-3008.

Received 20 November 1995; accepted in final form 23 February 1996.

\section{REFERENCES}

Aghajanian, G. K. And Rasmussen, K. Intracellular studies in the facial nucleus illustrating a simple new method for obtaining viable motorneurons in adult rat brain slices. Synapse 3: 331-338, 1989.

Akase, E., Alkon, D. L., And Disterhoft, J. F. Hippocampal lesions impair memory of short-delay conditioned cycblink in rabbits. Behav. Neurosci. 103: 935-943, 1989.

Akase, E., Thompson, L. T., And Disterhoft, J. F. A system for quantitative analysis of associative learning. II. Real-time software for MS-DOS microcomputers. J. Neurosci. Methods 54: 119-130, 1994.

ALKON, D. L. Voltage-dependent calcium and potassium ion conductances: a contingency mechanism for an associative learning model. Science Wash. DC 205: 810-816, 1979.

ALKON, D. L. Calcium-mediated reduction of ionic currents: a biophysical memory trace. Science Wash. DC 226: 1037-1045, 1984.

Alkon, D. L., Lederhendler, I., And Shoukimas, J. L. Primary changes of membrane currents during retention of associative learning. Science Wash. DC 215: 693-695, 1982.

Bank, B., De WeEr, A., Kuzirian, A. M., Rasmussen, H., and Alkon, D. L. Classical conditioning induces long-term translocation of protein kinase $\mathrm{C}$ in rabbit hippocampal CA1 cells. Proc. Natl. Acad. Sci. USA 85: $1988-1992,1988$.

Baranyi, A., Szente, M. B., And Woody, C. D. Propertics of associative long-lasting potentiation induced by cellular conditioning in the motor cortex of conscious cats. Neuroscience 42: 1-14, 1991.

BARNES, C. A. Involvement of LTP in memory: are we "searching under the street light"'? Neuron 15: 751-754, 1995.

Benardo, L. S. And Prince, D. A. Cholinergic pharmacology of mammalian hippocampal pyramidal cells. Neuroscience 7: 1703-1712, 1982.

BERGER, T. W. Long-term potentiation of hippocampal synaptic transmission affects rate of behavioral learning. Science Wash. DC 224: 627630,1984

Berger, T. W., Alger, B., And Thompson, R. F. Neuronal substrates of classical conditioning in the hippocampus. Science Wash. DC 192: 483485, 1976.

Berger, T. W., Rinaldi, P. C., Weisz, D. J., And Thompson, R. F. Singleunit analysis of different hippocampal cell types during classical conditioning of rabbit nictitating membrane response. J. Neurophysiol. 50: 1197-1219, 1983.

BLOCH, V. Facts and hypotheses concerning memory consolidation processes. Brain Res. 24: 561-575, 1970.

BLOCH, V. AND LAROCHE, S. Facts and hypotheses related to the search for the engram. In: Neurobiology of Learning and Memory, edited by G. Lynch, J. L. McGaugh, and N. M. Weinherger. New York: Guilford Press, 1994, p. 249-260.

Breese, C. R., Hampson, R. E., And Deadwyler, S. A. Hippocampal place cells: stereotypy and plasticity. J. Neurosci. 9: 1097-1111, 1989.

BUZSAḰi, G. Two-stage model of memory trace formation: a role for "noisy" brain states. Neuroscience 31: 551-570, 1989.

Byrne, J. H. Cellular analysis of associative learning. Physiol. Rev. 67: 329-439, 1987.

Carew, T. J., Castelluci, V. F., and Kandel, E. R. Sensitization in Aplysia: restoration of transmission in synapses inactivated by long-term habituation. Science Wash. DC 205: 417-419, 1979.

CAREW, T. J. AND SAHLEY, C. L. Invertebrate and memory: from behavior to molecules. Annu. Rev. Neurosci. 9: 435-487, 1986.

Castellucci, V. F., Pinkser, H., Kupferman, I., and Kandel, E. R. Neuronal mechanisms of habituation and dishabituation of the gill-withdrawal reflex in Aplysia. Science Wash. DC 167: 1745-1748, 1970.

Castro, C. A., Silbert, L. H., McNaughton, B. L., and Barnes, C. A. Recovery of spatial learning deficits after decay of electrically induced synaptic enhancement in the hippocampus. Nature Lond. 342: 545-548, 1989.

Christian, E. P. and Deadwyler, S. A. Behavioral functions and hippocampal cell types: evidence for two nonoverlapping populations in the rat. J. Neurophysiol. 55: 331-348, 1986.

Cohen, N. J. And Eichenbaum, H. Memory, Amnesia, and the Hippocampal System. Cambridge, MA: MIT Press, 1993. 
Cole, A. E. AND Nicoll, R. A. Acetylcholine mediates a slow synaptic potential in hippocampal pyramidal cells. Science Wash. DC 221: 12991301,1983

COLE, A. E. AND Nicoll, R. A. Characterization of a slow cholinergic postsynaptic potential recorded in vitro from rat hippocampal pyramidal cells. J. Physiol. Lond. 352: 173-188, 1984.

Colino, A. and Halliwell, J. V. Differential modulation of three separate $\mathrm{K}^{+}$-conductances in hippocampal CA1 neurons by serotonin. Nature Lond. 328: 73-77, 1987.

Colino, A. and Halliwell, J. V. Carbachol potentiates $Q$ current and activates a calcium-dependent non-specific conductance in rat hippocampus in vitro. Eur. J. Neurosci. 5: 1198-1209, 1994.

Coulter, D. A., Lo Turco, J. J., Kubota, M., Disterhoft, J. F., Moore, J. W., AND Alkon, D. L. Classical conditioning reduces amplitude and duration of calcium-dependent afterhyperpolarization in rabbit hippocampal pyramidal cells. J. Neurophysiol. 61: 971-981, 1989.

de Jonge, M. C., Black, J., Deyu, R. A., And Disterhoft, J. F. Learninginduced afterhyperpolarization reductions in hippocampus are specific for cell type and potassium conductance. Exp. Brain Res. 80: 456-462, 1990.

Deyo, R. A., Straube, K. T., And Disterhoft, J. F. Nimodipine facilitates associative learning in aging rabbits. Science Wash. DC 243: 809-811, 1989.

Disterhoft, J. F., Coulter, D. A., And Alkon, D. L. Conditioning-specific membrane changes of rabbit hippocampal neurons measured in vitro. Proc. Nat. Acad. Sci. USA 83: 2733-2737, 1986.

Disterhofi, J. F., Golden, D. T., Read, H. R., Collter, D. A., And AIKON, D. I. AHP reductions in rabbit hippocampal neurons during conditioning are correlated with acquisition of the learned response. Brain Res. 462: 118-125, 1988.

Disterhoft, J. F., Kwan, H. H., and Lo, W. D. Nictitating membrane conditioning to tone in the immobilized albino rabbit. Brain Res. 137: 127-143, 1977.

Disterhoft, J. F., Thompson, L. T., And Moyer, J. R., JR. Cellular mechanisms of associative learning in the hippocampus. In: Neural Bases of Learning and Memory in the Mammalian Brain, edited by J. Delacour. Paris: World Scientific Publishing, 1994.

Eichenbaum, H., Mathews, P., And Coilen, N. J. Further studies of hippocampal representation during odor discrimination learning. Behav. Neurosci. 103: 1207-1216, 1989a.

Eichenbaum, H., Wiener, S. I., Shapiro, M. L., and Cohen, N. J. The organization of spatial coding in the hippocampus: a study of neural ensemble activity. J. Neurosci. 9: 2764-2775, 1989b.

Gormezano, I. AND KeHOE, E. J. Classical conditioning and the law of contiguity. Adv. Anal. Behav. 2: 1-45, 1980.

Green, E. J. And Greenough, W. T. Altered synaptic transmission in dentate gyrus of rats reared in complex environments: evidence from hippocampal slices maintained in vitro. J. Neurophysiol. 55: 739-750, 1986.

HAAS, H. L. AND GREENE, R. W. Adenosine enhances afterhyperpolarization and accommodation in hippocampal pyramidal cells. Pfleugers Arch. 402: 244-247, 1984.

HaAs, H. L. AND Konnerth, A. Histamine and noradrenaline decrease calcium-activated potassium conductance in hippocampal pyramidal cells. Nature Lond. 302: 432-434, 1983.

Hampson, R. E., Heyser, C. J., and Deadwyler, S. A. Hippocampal cell firing correlates of delayed-match-to-sample performance in the rat. Behav. Neurosci. 107: 715-739, 1993.

Harvey, J. A., Gormezano, I., And Cool-Hauser, V. A. Relationship between heterosynaptic reflex facilitation and acquisition of the nictitating membrane response in control and scopolamine-injected rabbits. I. Neurosci. 5: 596-602, 1985.

HASSELmo, M. E. Neuromodulation and cortical function: modeling the physiological basis of behavior. Behav. Brain Res. 67: 1-27, 1995.

HASSELMO, M. E. AND SCHNELl, E. Laminar selectivity of the cholinergic suppression of synaptic transmission in rat hippocampal region CA1: computational modeling and brain slice physiology. J. Neurosci. 14: 3898-3914, 1994.

Hawkins, R. D., Abrams, T. W., Carew, T. J., and Kandel, E. R. A cellular mechanism of classical conditioning in Aplysia: activity-dependent amplification of presynaptic facilitation. Science Wash. DC 219: 400-405, 1983.

Hawkins, R. D., Kandel, E. R., and Siegelbaum, S. A. I earning to modulate transmitter release: themes and variations in synaptic plasticity. Annu. Rev. Neurosci. 16: 625-665, 1993.

HebB, D. O. The Organization of Behavior: A Neurophysiological Theory. New York: Wiley, 1949.

Hedlund, B. And Andersen, P. Alaproclate increases the excitability of hippocampal CA1 pyramidal cells and blocks the slow after-hyperpolarization. Pharmacol. Toxicol. 65: 185-188, 1989.

Hotson, J. R. AND Prince, D. A. A calcium-activated hyperpolarization follows repetitive firing in hippocampal neurons. J. Neurophysiol. 43: 409-419, 1980.

JeFFERy, K. J. AND Morris, R. G. M. Cumulative long-term potentiation in the rat dentate gyrus correlates with, but does not modify, performance in the water maze. Hippocampus 3: 133-140, 1993.

KIM, J. J. AND Faneslow, M. S. Modality-specific retrograde amnesia of fear. Science Wash. DC 256: 675-677, 1992.

Kim, J. J., Clark, R. E., and Thompson, R. F. Hippocampectomy impairs the memory of recently, but not remotely, acquired trace eyeblink conditioned responses. Behav. Neurosci. 109: 195-203, 1995.

KIRK, R. E. Introductory Statistics. Monterey, CA: Brooks/Cole, 1978.

KLEIN, M. AND KANDEL, E. R. Presynaptic modulation of voltage-dependent $\mathrm{Ca}^{2+}$ current: mechanism for behavioral sensitization in Aplysia californica. Proc. Natl. Acad. Sci. USA 75: 3512-3516, 1978.

Knöpfel, 'I., Vranesic, I., GaḦwiler, B. H., and Brown, D. A. Muscarinic and beta-adrenergic depression of the slow $\mathrm{Ca}^{2+}$-activated potassium conductance in hippocampal CA3 pyramidal cells is not mediated by a reduction of depolarization-induced cytosolic $\mathrm{Ca}^{2+}$ transients. Proc. Natl. Acad. Sci. USA 87: 4083-4087, 1990.

Korol, D. L., Abel, T. W., Church, L. T., Barnes, C. A., and MCNaughTON, B. L. Hippocampal synaptic enhancement and spatial learning in the Morris swim lask. Hippocampus 3: 127-132, 1993.

LANCASTER, B. AND ADAMS, P. R. Calcium-dependent current generating the afterhyperpolarization of hippocampal neurons. J. Neurophysiol. 55: $1268-1282,1986$.

Liv, Y. B., Disterhoft, J. F., AND SLATER, N. T. Activation of metabotropic glutamate receptors induces long-term depression of GABAergic inhibition in hippocampus. J. Neurophysiol. 69: 1000-1004, 1993.

LORENTE DE Nó, R. Studies on the structure of the cerebral cortex. II. Continuation of the study of the Ammonic system. J. Physiol. Neurol. 46: $113-177,1934$

LoTurco, J. J., Coulter, D. A., And Alkon, D. L. Enhancement of synaptic potentials in rabbit CAl pyramidal neurons following classical conditioning. Proc. Natl. Acad. Sci. USA 85: 1672-1676, 1988.

MADISON, D. V. AND NiCOLL, R. A. Control of the repetitive discharge of rat CA1 pyramidal neurones in vitro. J. Physiol. Lond. 372: 221-244, 1986a.

MADison, D. V. AND Nicoll, R. A. Actions of noradrenaline recorded intracellularly in rat hippocampal CA1 pyramidal neurones, in vitro. $J$. Physiol. Lond. 372: 221-244, 1986b.

Madison, D. V., Lancaster, B., AND Nicoi. ., R. A. Voltage clamp analysis of cholinergic action in the hippocampus. J. Neurosci. 7: 733-741, 1987.

Malenk A, R. C. AND Nicoll, R. A. Dopamine decreases the calciumactivated afterhyperpolarization in hippocampal CA1 pyramidal cells. Brain Res. 379: 210-215, 1986.

McCormick, D. A., Ci.ark, G. A., I.avond, D. G., and Thompson, R. F. Initial localization of the memory trace for a basic form of learning. Proc. Natl. Acad. Sci. USA 79: 2731-2735, 1982.

McGaugh, J. L. Time-dependent processes in memory storage. Science Wash. DC 153: 1351-1358, 1966.

McGautih, I. I. AND Alperin, H. P. Effects of electroshock on memory: amnesia without convulsions. Science Wash. DC 152: 665-666, 1966.

Mizumori, S. J. Y., McNaughton, B. L., Barnes, C. A., and Fox, K. B. Preserved spatial coding in hippocampal $\mathrm{C} \Lambda 1$ pyramidal cells during reversible suppression of CA3c output: evidence for pattern completion in hippocampus. J. Neurosci. 9: 3915-3928, 1989.

Moyer, J. R., JR., Deyo, R. A., And Disterhoft, J. F. Hippocampectomy disrupts trace eye-blink conditioning in rabbits. Behav. Neurosci. 104: 243-252, 1990.

MOYer, J. R., JR. AND DisterhofT, J. F. Nimodipine decreases calcium action potentials in rabbit hippocampal CA1 neurons in an age- and concentration-dependent manner. Hippocampus 4: 11-18, 1994.

Moyer, J. R., JR., Disterhoft, J. F., Black, J. P., And Yeh, J. Dihydropyridine-sensitive calcium channels in acutely-dissociated hippocampal CA1 neurons. Neurosci. Res. Commun. 15: 39-48, 1994.

Moyer, J. R., JR., Thompson, L. T., Black, J. P., And Disterhoft, J. F. 
Nimodipine increases excitability of rabbit CA1 pyramidal in an ageand concentration-dependent manner. J. Neurophysiol. 68: 2100-2109, 1992.

Moyer, J. R., JR., Thompson, L. T., AND Disterhoft, J. F. Trace eyeblink conditioning increases CA1 excitability in a transient and learning-specific manner. I. Neurosci. In press.

Olds, J., Disterhoft, J. F., Segal, M., Konblith, C. L., And Hirsh, $R$. Learning centers of rat brain mapped by measuring latencies of conditioned unit responses. J. Neurophysiol. 35: 202-219, 1972.

Olds, J. L., Anderson, M. L., McPhie, D. L., Staten, L. D., And Alkon, D. L. Imaging of memory-specific changes in the distribution of protein kinase-C in the hippocampus. Science Wash. DC 245: 866-869, 1989.

Olmstead, C. E., BESt, P. J., AND Mays, L. E. Neural activity in the dorsal hippocampus during paradoxical sleep, slow wave sleep, and waking. Brain Res. 60: 381-391, 1973.

Power, J. M., Thompson, L. T., Moyer, J. R., Jr., And Disterhoft, J. F. Increased synaptic responsiveness between CA3 and CA1 after trace eyeblink conditioning recorded in vitro. Soc. Neurosci. Abstr. 21: 1931, 1995.

RiouX, G. F. AND RoBinson, G. B. Hippocampal long-term potentiation does not affect either discrimination learning or reversal learning of the rabbit nictitating membrane response. Hippocampus 5: 165-170, 1995.

RoBINSON, G. B. Maintained saturation of hippocampal long-term potentiation does not disrupt acquisition of the eight-arm radial maze. Hippocampus 2: 389-395, 1992.

Sanchez-Andres, J. V. AND Alkon, D. L. Voltage-clamp analysis of the effects of classical conditioning on the hippocampus. J. Neurophysiol. 65: 796-807, 1991.

SCHARFMAN, H. E. Evidence from simultaneous intracellular recordings in rat hippocampal slices that area CA3 pyramidal cells innervate dentate hilar mossy cells. J. Neurophysiol. 72: 2167-2180, 1994.

SCHMAltz, L. W. AND Theios, J. Acquisition and extinction of a classically conditioned reflex in hippocampectomized rabbits (Oryctolagus cuniculus). J. Comp. Physiol. Psych. 79: 328-333, 1972.

SCholz, K. P. AND BYRne, J. H. Long-term sensitization in Aplysia: biophysical correlates in tail sensory neurons. Science Wash. DC 235: 685687, 1987.

Segal, M., Disterhoft, J. F., And Olds, J. Hippocampal unit activity during classical aversive and appetitive conditioning. Science Wash DC 175: 792-794, 1972.

Sharp, P. E., McNaughton, B. L., and Barnes, C. A. Enhancement of hippocampal field potentials in rats exposed to a novel, complex environment. Brain Res. 339: 361 365, 1985.
Solomon, P. R., Solomon, S. D., Vander SchaAf, E. V., and Perry, $\mathrm{H}$. E. Altered activity in the hippocampus is more detrimental to classical conditioning than removing the structure. Science Wash. DC 220: 329$331,1983$.

Solomon, P. R., Vander SchaAf, E. V., Thompson, R. F., And Weisz, D. J. Hippocampus and trace conditioning of the rabbit's classically conditioned nictitating membrane response. Behav. Neurosci. 100: 729744, 1986.

SQuire, L. Memory and Brain. New York: Oxford, 1987.

Storm, J. F. Potassium currents in hippocampal pyramidal cells. Prog. Brain Res. 83: 161-187, 1990.

Sutherland, R. J., Dringenberg, H. C., and Hoesing, J. M. Induction of long-term potentiation at perforant path dentate synapses does not affect place learning or memory. Hippocampus 3: 141 148, 1993.

Thompson, L. T. And Best, P. J. Place cells and silent cells in the hippocampus of freely-behaving rats. J. Neurosci. 9: 2382-2390, 1989.

Thompson, L. T., Disterhoft, J. F., AND Deyo, R. A. Nimodipine enhances spontaneous activity of hippocampal pyramidal cells in aging rabbits at a dose that facilitates learning. Brain Res. 535: 119-130, 1990.

Thompson, L. T., Moskal, J. R., And Disterhoft, J. F. Hippocampusdependent learning facilitated by a monoclonal antibody or D-cycloserine. Nature Lond. 359: 638-641, 1992.

Thompson, L. T., Moyer, J. R., JR., Akase, E., and Disterhoft, J. F. A system for quantitative analysis of associative learning. I. Hardware interfaces with cross-species applications. J. Neurosci. Methods 54: 109117, 1994.

Thumpson, L. T., MOYer, J. R., JR., AND Disterhoft, J. F. Trace eyeblink conditioning in rabbits demonstrates heterogeneity of learning ability both between and within age groups. Neurobiol. Aging. In press.

'THOMPSON, R. F. 'The neurobiology of learning and memory. Science Wash. DC 233: 941-947, 1986.

Walters, E. T. And Byrne, J. H. Associative conditioning of single sensory neurons suggests a cellular mechanism for learning. Science Wash. DC 219: 405-408, 1983.

Woody, C. D., GRUen, E., AND BIRT, D. Changes in membrane currents during Pavlovian conditioning of single cortical neurons. Brain Res. 539: 76-84, 1991.

Zola-Morgan, S., Squire, L. R., and Amaral, D. G. I esions of the hippocampal formation but not lesions of the fornix or the mammillary nuclei produce long-lasting memory impairment in monkeys. J. Neurosci. 9: $898-913,1989$. 